\title{
Competency-Based Education
}

\author{
Terry Oroszi \\ Department of Pharmacology \& Toxicology, Boonshoft School of Medicine, Wright State University, Fairborn, OH, USA \\ Email: terry.oroszi@wright.edu
}

How to cite this paper: Oroszi, T. (2020). Competency-Based Education. Creative Education, 11, 2467-2476.

https://doi.org/10.4236/ce.2020.1111181

Received: April 26, 2020

Accepted: November 24, 2020

Published: November 27, 2020

Copyright (C) 2020 by author(s) and Scientific Research Publishing Inc. This work is licensed under the Creative Commons Attribution International License (CC BY 4.0).

http://creativecommons.org/licenses/by/4.0/ (c) (i) Open Access

\begin{abstract}
Competency-based education (CBE) is an innovative advance in higher education that organizes academic content or delivery according to competencies, what a student knows and can manage, rather than conforming to a more traditional system. CBE offers students the chance to use past experiences, skills, and knowledge to complete a course, get a degree, or complete the training needed to pursue their goals. Student debt is increasing, and academic institutions must transform to accommodate the needs of the new students. Originally only found at for-profit institutions, a greater number of non-profit universities are adopting competency-based education because it offers delineated learning outcomes and appeals to student's experiences. Online competency-based education can provide a method to decrease failure in completion, the flexibility of the program can work with a student's schedule. Global demands for virtual options are making it difficult for traditional universities to resist the online phenomenon. The development of online competency-based programs requires new approaches to the curriculum design process. One proven method of CBE instruction was implemented at a medical school in Ohio, USA. The formula used is outlined in this paper, allowing others to design their own. The benefits to the student include the ability to test out of the material they are familiar with and focus only on the new material. The school will still require the student to take the course, so revenue is not lost, and they get the benefit of helping their students. In an era when recruitment stems from word of mouth, the adoption of this method will encourage others to join the program.
\end{abstract}

\section{Keywords}

Competency-Based Education, CBE, Education Methodology, Online Learning CBE Model

\section{Introduction}

The purpose of this paper was to examine an alternative method of instruction 
while offering students the opportunity to use their competency in a field to complete the course or degree. Testing out of a course has been a long-time method to award the student's knowledge, but if the student has not taken that exact course, it is unlikely they will know enough to test out. Competency-based Education (CBE) in the way proposed in this paper will allow the students to test out of sections in which they are competent so they can focus on the new material. Testing out of a course helps the student, but the revenue the school receives would be zero. The proposed model will still collect revenue, so it is a win-win for both the student and the school.

Competency-based education is an innovative approach in higher education that organizes academic content or delivery according to competencies, what a student knows and can do, rather than following a more traditional scheme, such as by course (U.S. Department of Education, 2014; Smith, 2013). Competency learning assesses student learning, not time spent in a classroom (Fain, 2009). A program organized by competency measures student progress using a clock or credit hours and while it may not be the blueprint for the future, it will demonstrate mastery of specific criteria (Ordonez, 2014; Palardy \& Eisele, 1972). Ordonez (2014) mentions a competency-based degree program that started in 2013 that started with 500 students which demonstrates a significant interest in alternative instruction (Baartman, Bastiaens, Kirschner, \& Van, 2006).

\subsection{Cost Savings}

The rapid development of online teaching technology has resulted in traditional learning styles to blend using virtual convenience and combining competency-based education with online instruction which accommodates several kinds of learners and makes sense (Wu, Kuo, Wu, \& Wu, 2006; Trout, 2016). A set of researchers compared the effects of virtual learning versus traditional learning to achieve competency-based clinical skills and found that the blending of both methods provided the best results, facilitating the knowledge transfer necessary for the rapid development of patient care and lifelong learning (Mosalanejad, Shahsavari, Sobhanian, \& Dastpak, 2012).

\subsection{Flexibility Leads to Increased Matriculation}

Online competency-based education can provide a method to decrease failure in completion, the flexibility of an online program can work with a student's schedule and teaching online programs mean less overhead and excess profit. The online option is cheaper because the costs are limited to the instructor, and any online technology needed. There are several hidden costs when teaching in a classroom, building cost to include: maintenance, heating and air, janitorial services and repair are examples of hidden expenses that are removed when teaching online. This allows for lower tuition and increased enrollment, leading to graduation.

The Council on Education for Public Health (CEPH) predicts that competency-based education will radically change the traditional time-based education 
system in the United States and make programs such as those described more reputable so students can be proud of their degree and school (Bennett, \& Walston, 2015). If a student is happy in their degree program they have a greater chance as success.

Higher education must transform to accommodate the wants of the millennium (Ordonez, 2014). Learners are leading the current change in education, and they are doing this with their dollars. Student debt is increasing, the cost of college tuition is mounting, and the number of jobs calling for a college degree is on the rise, so the learners are seeking alternative means of education. CBE provides an alternative to the costly classroom-driven curricula. Disruption of the traditional educational method will win over, and it is essential to be part of the change at the start, to aid in policy development (Smith, 2013).

\subsection{Increased Revenue}

The opportunities for increased revenue through online teaching are why more schools are selecting this route. This is made clear when universities like Indiana University invest $\$ 8$ million to design online courses (Smith, 2013). The Department of Education has supported the growth and development of new education delivery options (Ordonez, 2014). Allowing students to use their wealth of information on a subject to count toward a degree will get them in the door, the ability to take courses while maintaining a job that gave them that knowledge through an online system will keep them enrolled.

In 2020 when COVID 19 forced programs to go online or close the department of Pharmacology and Toxicology was prepared. Three years prior the department started an online and CBE curriculum that meant the transition caused minimal discomfort and the revenue streams continued. When the online track was implemented growth was slow and resistance to teach online was everywhere. Despite low enrollment numbers, persistence and determination kept the program alive.

The same department listed above started a chemical biological radiological and nuclear (CBRN) defense certificate program grounded in CBE and $100 \%$ online in 2012. Several of the students have past military experience in CBRN and we chose to credit them by offering the CBE method. The program has grown to become internationally recognized, accepting military-trained students from countries such as Canada, France, and New Zealand. There is no doubt that the revenue generated stems from the fact that the courses are CBE and online.

\section{Background}

Before diving into the new model, it is best to describe the general model of CBE and its benefits. CBE offers students the opportunity to pursue affordable education and training using past experiences, skills, and knowledge to aid them in this endeavor (Rainwater, 2016). CBE, or at least a form of it, maybe one of the oldest instructional models (Irvine \& Kevan, 2017). The introduction of compe- 
tency-based programs in the education system in the US started in the 1960s with innovative teacher education programs. A decade later vocational education programs became popular again, and because of cost savings and easy access online, hybrid, and adaptive learning technology have become popular (Nodine, 2016).

\subsection{The Roots of CBE, Online and Hybrid Training}

Originally only found at for-profit institutions, a greater number of non-profit universities are adopting competency-based education (Ordnez, 2014). The University of Michigan, Purdue University, and the University of Wisconsin are just a few schools undertaking the CBE transition (Fain, 2009). The CBE model is gaining popularity because it offers delineated learning outcomes and appeals to students because they receive credit for past experiences and knowledge.

Existing methods of teaching can be integrated into competency-based instructions (Smith, 2013). Classroom learning can include online testing and allow the students to test out on sections in which they have subject matter expertise. The course can be taught in a hybrid fashion, with online components, such as webinars, and videos. Online training can mimic the more traditional methods of faculty training by offering synchronous face-to-face courses using several online meeting options. Professors can offer one-on-one sessions with their students. Faculty may resist new teaching methods and training for CBE development can be costly, but the benefits make it worth it. In fact, recording learning sessions decrease duplication of effort on behalf of the educators (Kim, Park, \& O’Rourke, 2017; Stone-MacDonald \& Douglass, 2015).

\subsection{Issues}

As we move forward with online education, consideration of grade inflation and completion, while providing a meaningful program, must be at the forefront of our thoughts (Smith, 2013). When the University of Oklahoma College of Public Health integrated competency-based education into their curriculum several issues were not initially identified. According to Bennett and Walston (2015), they believed their faculty were not consulted during the development and adoption of the competencies resulting in their lack of interest and understanding. Due to this lack of interest and understanding, the course content did not change so the measurement of the competency was not possible. They claimed that this was not atypical, similar barriers have affected other institutions implementing a competency-based method of instruction.

The competencies should measure the progress of the student with intermittent evaluation methods that measure the progress of the students for the students, instructors, and program directors (Bennett \& Walston, 2015). The ability to measure the success of a student through online CBE instruction is the reason faculty resist this method. Tools to lock down computers during a test to prevent the student from searching the internet for answers, cameras on during testing, and other means of identifying the student and their integrity have made this a 
moot issue. If the professor is really concerned, they have the means to act on their uneasiness.

Other critics of CBE are concerned with the loss of student-professor interactions, and fewer classes (Shapiro, 2014). A student can leave with a false understanding of the content and construct their interpretation of the material under competency-based scrutiny. Lozano and his group (2012) point out that although the concept of competence does have its weaknesses; however, they can be overcome with the addition of a capabilities approach. Capabilities take competence a step further, adding skills they feel are important for individuals to lead a responsible life becoming a citizen, not just a student.

\subsection{Evaluation Methods}

One method of evaluation of competency in a systems-based practice was created for students affiliated with Harvard Medical School. Before the module started the learners completed a questionnaire that assessed their knowledge of patient care. Throughout the module, multiple-choice questions were interspersed with discussions of the case. In the end, they repeated the questionnaire they took at the start of the case (Eskildsen, 2010). Although Harvard Medical used the questionnaire to measure pre and post-learning, it also used intermediate assessment methods to test progress. To assess a competency using only one method may not be adequate (Baartman et al., 2006). The department of Neurosurgery at Johns Hopkins uses the competency-based method to evaluate surgical skills for its residency program (Long, 2000).

\subsection{CBE Curriculum Design}

The development of online competency-based programs requires new approaches to the curriculum design process. This new framework for designing courses is based on competencies, knowledge, and skills, rather than class time (Kelly \& Columbus, 2016, Voorhees, 2001). The premise behind CBE is that the student will demonstrate acquisition of the required knowledge, skills, and attitudes expected for the educational module before leaving the classroom (Hodges, Konicki, Talley, Bordelon, Holland, \& Galin, 2019).

When designing a curriculum involving pharmacology instruction to paramedical students, the program opted for the non-traditional CBE method. The pharmacology course included six objectives, including one tailored by the student. Assessment methods included study questions, projects, quizzes, and exams. The exams were criterion-referenced, and eighty-five percent mastery was required. Final exams were patient-drug case studies, testing the ability to apply material mastered. Outcomes indicated an encouraging change in student attitudes and grade statistics (Keuhnelian \& Kerns, 1974). The Accreditation Council for Graduate Medical Education (ACGME) supports competency-based graduate medical education programs and believes it ensures the residents are competent to practice a specialty (Whitcomb, 2002). 


\section{Methodology}

Hossein Vatanpour (2012), belies the current method of education in pharmacy schools is lecture-based. He states the inadequacy of this method to the graduates' work. In pharmacy, problem-solving ability is needed, not purely declarative knowledge. The solution is problem-based learning (PBL), an aspect of competency-based education. PBL is used to aid anticipated learning outcomes and practice competencies for entry-level pharmacists and is an active approach to enhance communication and decision-making skills, greater problem-solving capabilities, effective critical thinking abilities. Several pharmacy courses including pharmacotherapeutics, pharmacology, and toxicology lend itself well to the competency-based methods, but not all the basic science courses benefit from non-traditional learning styles (IBID).

One proven method of CBE instruction was implemented at a medical school in Ohio, USA. The graduate program accepted international students with medical and pharmacology degrees, so much of what they studied in a biodynamics/biokinetics class was information they had gleaned from their earlier studies, but not all the content, so testing out of the course was not possible. At the same time the program was starting an online MS degree in Pharmacology \& Toxicology and changed the instruction method to one of competency-based education allowed students to test out of the sections, and at the same time make this a course a student could do completely online (see Figure 1).

1) A library of questions is created for each week's worth of content. A ungraded pretest (assessment before instruction of new material) and posttest (an assessment of knowledge post instruction) both draw from the same library of questions. By doing so, the students will be able to assess their ability to do the posttest. If the library of questions is small, a question in the pretest may be present in the posttest. The library size must be large enough to decrease the chances of duplicates. This educational model allows students to work at their own pace and receive credit for previous experience (Gravina, 2017).

2) If a student believes they are familiar with the material for the week they can take the pretest, and based on their score and confidence, take the posttest without examining the course material, or attending class.

3) The course material can be a combination of videos, handouts, PowerPoints, textbooks as well as face-to-face brick and mortar classroom or virtual classroom. This will allow the instructor to offer the class with or without classroom time. The availability of online educational learning materials can be available online to students whenever they need to access them (Nodine, 2016).

4) The posttest grades are totaled and any additional grades, such as attendance and other assignments included. This aggregate becomes the final grade.

The benefits to the student include the ability to test out of the material they are familiar with and focus only on the new material (Gravina, 2017). The school will still require the student to take the course, so revenue is not lost, and they get the benefit of helping their students. In an era when recruitment stems from 


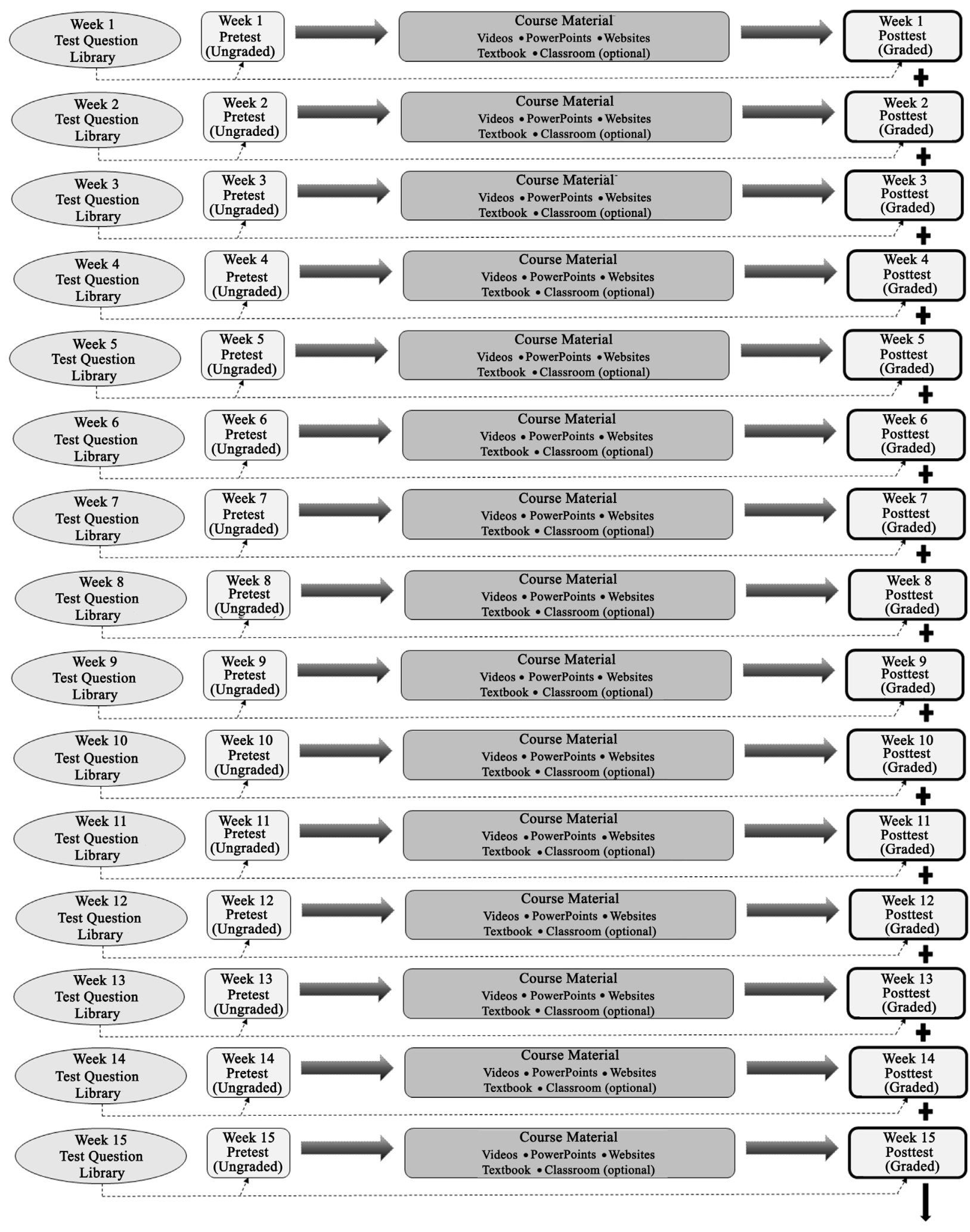

Posttests scores are totaled, and the grade assigned.

Figure 1. An example of Competency Based Education graduate course design. The Pretest and posttest questions are randomly chosen from the same pool. This model allows the course to be instructed both online and in the classroom. 
word of mouth, the adoption of this method will encourage others to join the program.

\section{Summary}

An all-inclusive approach to education is needed, traditional education, competency-based, problem-solving, and the capabilities approach all have their place in education, depending on the materials and the audience. This paper defined competency-based education. It outlined the pros and cons of CBE and provided a template for interested parties to create their own CBE course. One method is not the answer to everything. An awareness of alternative methods increases the fear of plagiarism or ethics indiscretions decrease; more education programs will start adopting methods like CBE. Competition with online programs will continue, and the virtual classroom will win over due to its ease, cost, and availability.

\section{Impact}

Alternative models of instruction are needed. Competency-based education and online instruction can meet the global demands for virtual options and will make it difficult for traditional universities to resist the online phenomenon (O’Neill, Singh, \& O'Donoghue, 2004). This universal change from teacher-centered to learner-centered instruction is the premise behind competency-based instruction. Should traditional universities be preserved is the question that Bulajeva, Duobliene, \& Targamadze (2009) asked themselves when studying graduate STEM students in Lithuania. They follow the oldest method of instruction known, the Oxford model. The Oxford model exemplifies traditional knowledge, learning and culture. The German model of learning came next. This system of gaining knowledge incorporated a systematic, institutionalized research, investigation, and critical knowledge approach. This model was less social than the British one and was geared toward the personal performance of the student and stressed competencies. One can say competency-based education derived from this model, therefore, has roots from the 19th century. The French have a Napoleonic university model that focused on professional education, similar to CBE. Bulajeva et al. (2009), state that American universities try to respond to rapidly changing technologies and societal demands and focus on professional competencies.

\section{Conflicts of Interest}

The author declares no conflicts of interest regarding the publication of this paper.

\section{References}

Baartman, L. K. J., Bastiaens, T. J., Kirschner, P. A., \& van der Vleuten, C. P. M. (2006). The Wheel of Competency Assessment: Presenting Quality Criteria for Competency 
Assessment Programs. Studies in Educational Evaluation, 32, 153-170. https://doi.org/10.1016/j.stueduc.2006.04.006

Bennett, C. J, \& Walston, S. L. 1. (2015). Improving the Use of Competencies in Public Health Education. American Journal of Public Health, 105, S65-S67. https://doi.org/10.2105/AJPH.2014.302329

Bulajeva, T., Duobliene, L., \& Targamadze, V. (2009). Transformation of University: Towards Pragmatism and Competence-Based Education. Pedagogy Studies/Pedagogika, 93, 9-16.

Eskildsen, M. A. (2010). Review of Web-Based Module to Train and Assess Competency in Systems-Based Practice. Journal of the American Geriatrics Society, 58, 2412-2413. https://doi.org/10.1111/j.1532-5415.2010.03167.x

Fain, P. (2009). At Public Universities: Less for More. The New York Times.

Gravina, E. W. (2017). Competency-Based Education and Its Effect on Nursing Education: A Literature Review. Teaching and Learning in Nursing, 12, 117-121. https://doi.org/10.1016/j.teln.2016.11.004

Hodges, A. L., Konicki, A. J., Talley, M. H., Bordelon, C. J., Holland, A. C., \& Galin, F. S. (2019). Competency-Based Education in Transitioning Nurse Practitioner Students from Education into Practice. Journal of the American Association of Nurse Practitioners, 31, 675-682. https://doi.org/10.1097//XX.0000000000000327

Irvine, C. K. S., \& Kevan, J. M. (2017). Competency-Based Education in Higher Education. In Handbook of Research on Competency-Based Education in University Settings (pp. 1-27). IGI Global. https://doi.org/10.4018/978-1-5225-0932-5.ch001

Kelly, A. P., \& Columbus, R. (2016). Innovate and Evaluate: Expanding the Research Based for Competency-Based Education. Washington DC: Center for Higher Education Reform.

Keuhnelian, A. M., \& Kerns, R. B. (1974). Mastery-Based Personalized Instruction in Pharmacology.

Kim, S., Park, C., \& O’Rourke, J. (2017). Effectives of Online Simulation Training: Measuring Faculty Knowledge, Perceptions, and Intention to Adopt. Nurse Education Today, 51, 102-107. https://doi.org/10.1016/j.nedt.2016.12.022

Long, D. M. (2000). Competency-Based Residency Training: The Next Advance in Graduate Medical Education. Academic Medicine, 75, 1178-1183. https://doi.org/10.1097/00001888-200012000-00009

Lozano, J. F., Boni, A., Peris, J., \& Hueso, A. (2012). Competencies in Higher Education: A Critical Analysis from the Capabilities Approach. Journal of Philosophy of Education, 46, 132-147. https://doi.org/10.1111/j.1467-9752.2011.00839.x

Mosalanejad, L., Shahsavari, S., Sobhanian, S., \& Dastpak, M. (2012). The Effect of Virtual versus Traditional Learning in Achieving Competency-Based Skills. Turkish Online Journal of Distance Education, 13, 69-75.

Nodine, T. R. (2016). How Did We Get Here? A Brief History of Competency-Based Higher Education in the United States. The Journal of Competency-Based Education, 1, 5-11. https://doi.org/10.1002/cbe2.1004

O’Neill, K., Singh, G., \& O’Donoghue, J. (2004). Implementing eLearning Programmes for Higher Education: A Review of the Literature. Journal of Information Technology Education: Research, 3, 313-323. https://doi.org/10.28945/304

Ordonez, B. (2014). Competency-Based Education: Changing the Traditional College Degree Power, Policy, and Practice. New Horizons in Adult Education \& Human Resource Development, 26, 47-53. https://doi.org/10.1002/nha3.20085 
Palardy, J. M., \& Eisele, J. E. (1972). Competency Based Education. The Clearing House, 46, 545-548. https://doi.org/10.1080/00098655.1972.11478097

Rainwater, T. S. M. (2016). Teaching and Learning in Competency-Based Education Courses and Programs: Faculty and Student Perspectives. The Journal of Competency-Based Education, 1, 42-47. https://doi.org/10.1002/cbe2.1008

Shapiro, J. (2014). Competency Based Degrees: Coming Soon to a Campus near You. Washington, DC: Chronicle of Higher Education.

Smith, B. (2013). Perspectives: Unconventional Wisdom. Change: The Magazine of Higher Learning, 45, 33-39. https://doi.org/10.1080/00091383.2013.749145

Stone-MacDonald, A., \& Douglass, A. (2015). Introducing Online Training in an Early Childhood Professional Development System: Lessons Learned in on State. Early Childhood Education Journal, 43, 241-248. https://doi.org/10.1007/s10643-014-0649-2

Trout, G. (2016). E-Learning and Online Training: Keeping up with a Revolving Workplace. Professional Safety, 61, 34-36.

U.S. Department of Education (2014). Competency-Based Education Programs-Questions and Answers. Washington, DC: U.S. Department of Education.

Vatanpour, H. (2012). To What Extent Would PBL Be Best Incorporated into a Pharmacy Curriculum? Iranian Journal of Pharmaceutical Research, 11, 999-1000.

Voorhees, R. (2001). Measuring What Matters: Competency-Based Learning Models in Higher Education. New Directions for Institutional Research, Number 110. San Francisco, CA: Jossey-Bass. https://doi.org/10.1002/ir.13

Whitcomb, M. E. (2002). Competency-Based Graduate Medical Education? Of Course! But How Should Competency Be Assessed? Academic Medicine, 77, 359-360.

https://doi.org/10.1097/00001888-200205000-00001

Wu, P., Kuo, C., Wu, P., \& Wu, T. (2006). Design a Competence-Based Networked Learning System: Using Sequence Control as Example. Current Development in Technology-Assisted Education, 2, 787-791. 